\title{
Neural Network based Modeling and Simulation for Estimation of Maximum Transformer Inrush Current
}

\author{
Puneet Kumar Singh \\ Department of Electrical Engineering \\ DEI, Dayalbagh
}

\author{
D.K. Chaturvedi \\ Department of Electrical Engineering \\ DEI, Dayalbagh
}

\begin{abstract}
Inrush current is a very important phenomenon which occurs in transformer during energization at no load. It depends on several factors like magnetizing properties of magnetic material, resistant and inductance of primary winding, supply frequency, switching angle of circuit breaker, applied voltage etc. Objective of this study is to estimate the maximum value of transformer inrush current. Measurement of inrush current is difficult issue for large rating of transformer under different switching conditions. Therefore this study is used to demonstrate Artificial Neural Network (ANN) for modeling and simulation. This helps in prediction of maximum inrush current for large rating of transformer. Back Propagation with Levenberg-Marquardt (LM) algorithm was used to train the ANN architecture and same was tested for the various data sets. For effective training of ANN various operating conditions are considered. These are Transformer VA rating, Applied Voltage, switching angle and Remnant flux. This study was carried out to develop ANN model in a generalize manner which can be utilize for predicting maximum value of current and harmonic for any single phase transformer provide core material and frequency remains same.
\end{abstract}

\section{Keywords}

Transformer, Inrush Current, ANN, Modeling, Simulation, Harmonic.

\section{INTRODUCTION}

Large numbers of mal operations in an integrated PS require smart prediction and protection, to ensure its healthy operations. These mal operations result over voltages, symmetrical \& unsymmetrical faults, internal resonances, and lightning impulse stresses. Hazardous operations manifest as electromagnetic transients and are usually difficult to accurately predict. So, Wavelet transform and neural network is used to classify transient phenomena [15]. Real time transient of transformer differential relay [7, 9, and 10], current based differential protection [13, 16], controlled switching planning for circuit breaker [17] and Protection Device with improved technology comes in the market to overcome these mal operations but sometimes system feels unhealthy. Therefore, protection device performs erroneous behavior because they are unaware with inrush current of system [1]. Power differential method is used for discriminate fault current and inrush current of transformer [8].Transformer is very important part of power system because its cost relatively higher than other parts in power system.

Inrush current was calculated by numerical calculation [3], semi analytic solution [50], analytic formula, coupled electromagnetic model [6] and detection algorithm for digital computer [2]. ANN Model is used for modeling and simulation which gives relatively good performance. This study is extension of it [23-24].

Single phase [4] and three phase [5] transformer has been used for investigating inrush current. It was investigated in offshore electrical systems [11], substations [12], wind farm grid connections. It was also investigating in different operating condition $[12,21,18, \& 22]$.

\section{OBJECTIVE OF STUDTY}

The main objective of this study was to estimate maximum inrush current and second harmonic current based on different operating conditions and develop an ANN model. Inrush current can be measured by instruments for small rating of transformer but measurement issues arises in large rating of transformer due to large electromagnetic transients forces. Hence, there is a need of a system which can predict maximum inrush current and harmonics for large rating of transformer.

\section{METHODOLOGY}

In this paper, a single-phase transformer was simulated in MATLAB. Simulation was performed to obtain various data sets. These data sets were then utilized to develop neural network (ANN) model for estimating the maximum transformer inrush current and harmonic current content for discrimination.

\subsection{Data Collection}

Simulation was carried out for collecting various data sets using MATLAB Model as shown in figure 1. This model considers data of first few cycles. Then MAX command is used for evaluating maximum value from data which was obtained during simulation. These data sets include values of inrush current and harmonic content at different operating conditions but frequency remains constant i.e. $50 \mathrm{~Hz}$. These conditions were VA rating, frequency, primary voltage and switching angle. All these data sets were prepared on constant value of saturation or core property remains same throughout the process. Ranges of different operating conditions in simulation are:

Transformer rating $=51015255075100$ KVA;

Frequency $=50 \mathrm{~Hz}$;

Applied Voltage $=416110003300036000 \mathrm{~V}$;

Switching Angle = 090120 in degrees;

Remanent flux $=00.50 .8 \mathrm{~Wb}$; 


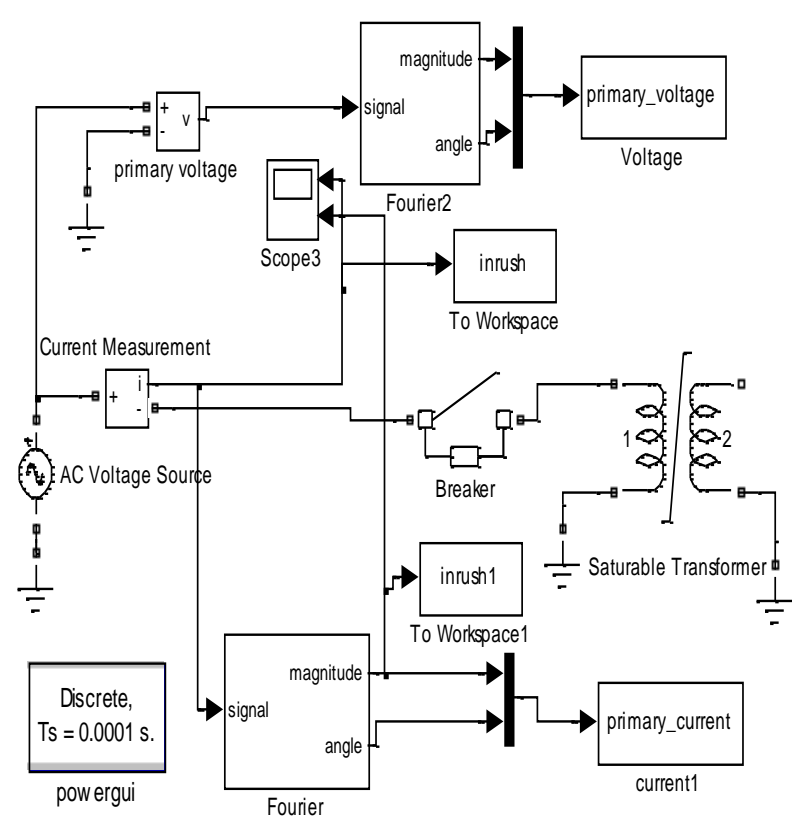

Fig 1: MATLAB Simulink Model for evaluating transformer inrush current

\subsection{Artificial Neural Network}

An Artificial Neural Network (ANN) is a collection of large numbers of processing elements, called artificial neurons. Neurons are linked to other neurons by associated weighted connections in neural network. Each neuron processes weighted inputs to its activation function, and then its output is forwarded to next layer of neurons. Every Artificial neural network consists of three types of layers namely input layer, hidden or processing layer and output layer. The number of neurons in the input layer is same as the number of input variables. There is no general rule to decide the number of neurons in hidden layer(s) but the number of neurons in the hidden layer increased with nonlinearity and complexity of data. The number of neurons in the output layer is same as the number of output variables. Furthermore, there are two type of outputs namely actual output and target output. Actual output refers to the output of output layer in ANN and the Target is the desired output for which the ANN is trained. The difference between the actual output and the target output is the error or tolerance. The neural network has the ability to learn from the experimental data by adjusting weights to acquire knowledge and can build the knowledge available for later use. By allocating appropriate values to the weights after during training, an Artificial Neural Network (ANN) can carry out complicated operations based on its inputs. ANN models need to be well trained with acceptable accuracy prior to use for further data investigation. Learning process is accomplished through particular training algorithms that are developed to copy the learning method of biological systems [25-27].

\subsection{Back Propagation Learning Algorithm for Neural Networks}

One of the most frequently used training algorithms for ANN model is feed forward back propagation [25-27]. In this model, the output variable is a function of all nodes in the hidden layer and associated weights between hidden layer to output layer, and the output of each node in the hidden layer is a function of input variables and associated weights between
Input layer to hidden layer. No interaction is allowed between adjacent nodes of the same layer. This method is easy to learn, understand and easy to program. With this approach, the error is propagated backwards according to the delta rule [27]. One method to adjust weights in back propagation algorithm is to use gradient descent learning rule, which, ideally, requires infinitesimal changes in the weights and is called Delta Rule. The weight of input and hidden nodes will be adjusted based on the error during the training. ANN models use about approximately seventy percentages of the same data sets numerous times for training. The desired output and actual output are used during the weights updating repeatedly until the error or tolerance level reaches in range of predetermined and acceptable level. Each iteration of finding ANN output is called epoch. This algorithm can be expressed briefly in the form of a pseudo-code as given below:

Start

Initialize training parameter ' $r$ '.

Calculate ANN output for given input.

Calculate error.

If error is not acceptable

Update weights

End.

Repeat until performance is acceptable.

For each sample input, compute the resulting output.

Compute $\varepsilon$ for nodes in the output layer using

$\varepsilon=\mathrm{D}-\mathrm{O}$

Where D represents the desired output and $\mathrm{O}$ represents the actual output of the neuron

Compute $\varepsilon$ for all other nodes using

$$
\varepsilon_{j}=\sum_{k} W_{j \rightarrow k} O_{k}\left(1-O_{k}\right) \varepsilon_{j}
$$

Compute weight changes for all weights using

$$
\Delta W_{i \rightarrow j}=r O_{j} O_{k}\left(1-O_{j} \varepsilon_{j}\right)
$$

Add up the weight changes to the weights.

\subsection{Levenberg - Marquardt (LM) Approximation}

The ordinary Back Propagation algorithm suffers from the serious drawbacks of slow convergence and incapability to avoid local minima. So, BP with Levenberg - Marquardt (LM) approximation is used in this study. LM learning rule uses an approximation of the Newton's method to obtain improved performance [26]. This method is comparatively faster but requires more memory. The $\mathrm{LM}$ update rule is:

$$
\Delta W=\left(J^{T} J+\mu . I\right)^{-1} J^{T} e
$$

Where $\mathrm{e}$ is an error vector, $\mathrm{J}$ is the Jacobean matrix of derivatives of each error to each weight and $\mu$ is a scalar. If the $\mu$ is very large, the above expression becomes the Gradient Descent method while it is small the above expression becomes the Gauss Newton method. The Gauss Newton method is comparatively faster and more precise near error minima. Hence, the aim is move towards the Gauss - Newton as quickly as possible. The $\mu$ is decreased after each successful step and increased only when the step increases the error or tolerance. 


\subsection{Normalization of Training Data}

To avoid saturation in network [26] and proper training the input and output variables were normalized in between 0.1 to 0.9 by a program written in MATLAB.

\subsection{Network Training and Development of Model}

The proposed neural network as shown in fig. 2 use 4 input variables and two output variables for training. The input variables are (1) VA transformer rating, (2) Applied Primary Voltage, (3) Switching angle of circuit breaker, (4) Remanent flux. These input variables were connected with hidden layers and 12, 9 and 7 successive neurons in hidden layers 1,2 and 3. Hidden layers were then connected with output layer with two neurons. One output refers to maximum transformer inrush current and second refers to estimation of maximum second harmonic current content. The network was trained in MATLAB environment. This software is chosen due to its capabilities and ability to provide solutions in technical computing. Among various training algorithms available, Levenberg-Marquardt (LM) training function was selected because it has the fastest convergence ability [27]. Mathematically, it can be defined by equation 5 .

$$
i_{\text {inrush }}=f_{A N N}\left(V A, V_{n}, \theta_{n}, \Phi r_{n}\right)
$$

Where,

$\mathrm{n}=$ number of iteration,

VAn=Rating of Transformer in Volt-Ampere,

$\mathrm{Vn}=$ Applied voltage at primary side,

$\theta \mathrm{n}=$ Switching angle of circuit breaker,

Фrn= Remnent flux,

iinrush $=$ [iinrushmax iinrush_second_harmonic $]$

iinrushmax $=$ Estimate the maximum of inrush current

iinrush_second_harmonic $=$ Estimate the maximum second harmonic current content

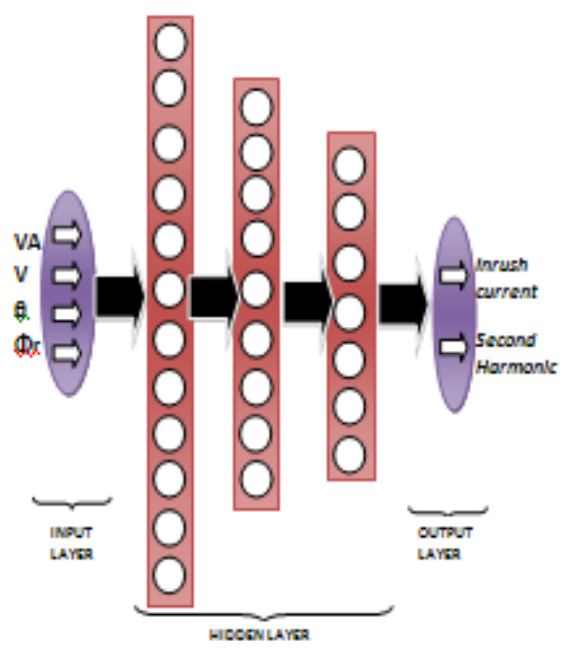

Fig 2: ANN1 Structure (4-12-9-7-2) for Inrush current Modeling

\section{RESULTS AND DISCUSSION}

ANN Model was trained by various data sets with different operating conditions as shown in fig. 3 and 4. Performance of ANN during training with respect to number of epochs is shown in fig. 5. To know the accuracy of ANN Model, Output data of ANN was compared with the data sets which were used for training ANN Model for estimating maximum inrush current and second harmonic current content as shown in fig. 6 and 7 respectively. This ANN model is developed in such a manner that it is used to estimate both values i.e. maximum inrush current and second harmonic current content. Simulation results show that minimum peak of inrush current and second harmonic current content obtained around $120 \mathrm{o}$ switching angle.

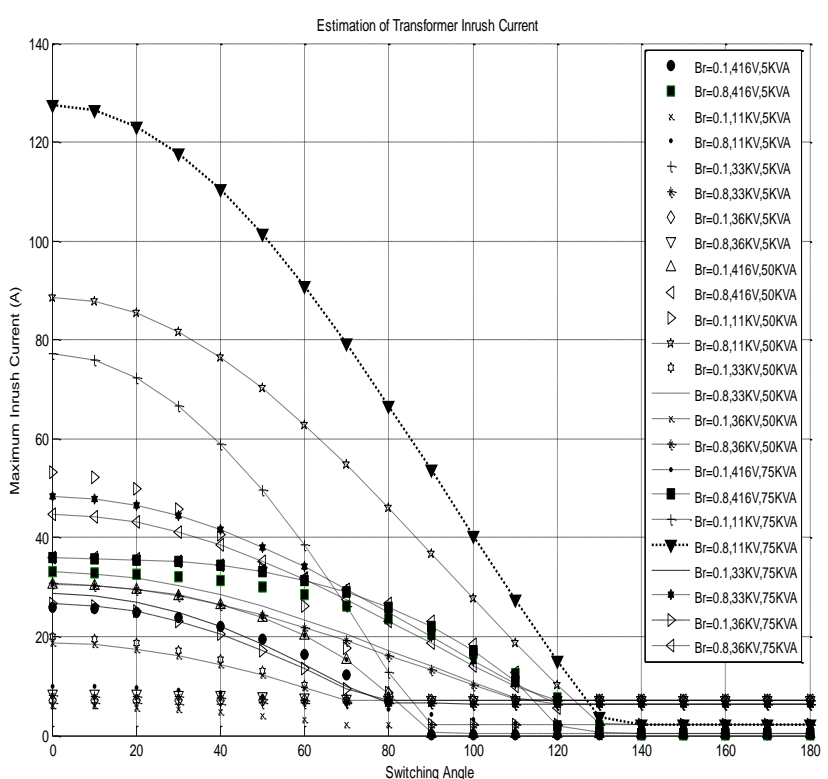

Fig 3: Inrush current with respect to switching angle with different operating conditions

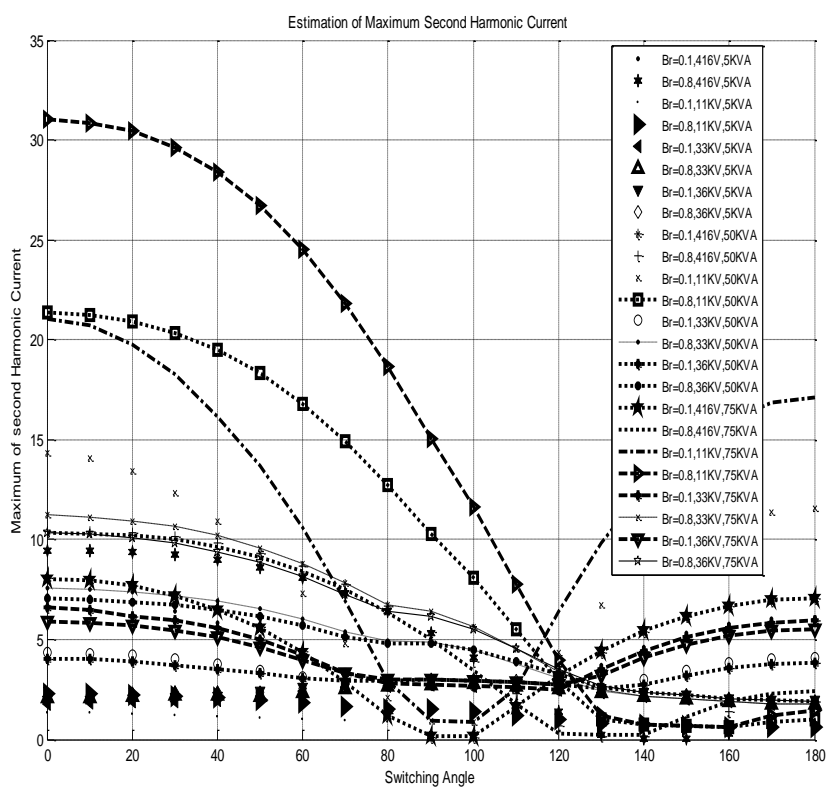

Fig 4: Second harmonic current content with respect to switching angle on different operating conditions 


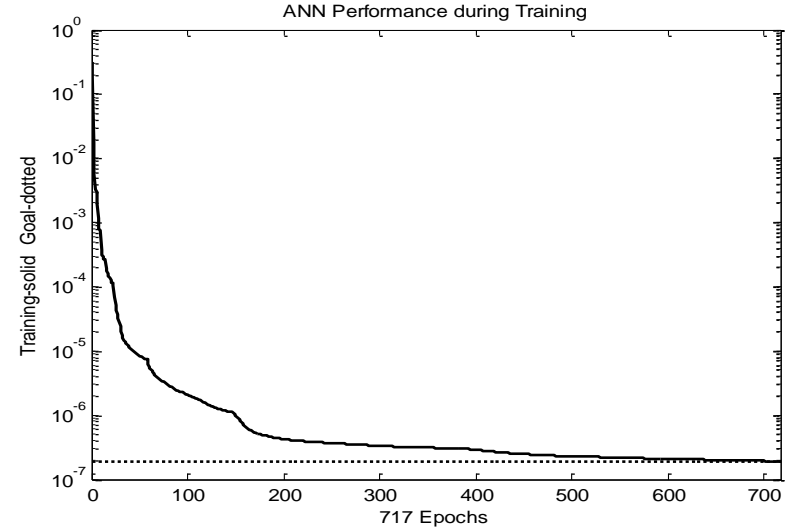

Fig 5: Performance of ANN during training with epoch

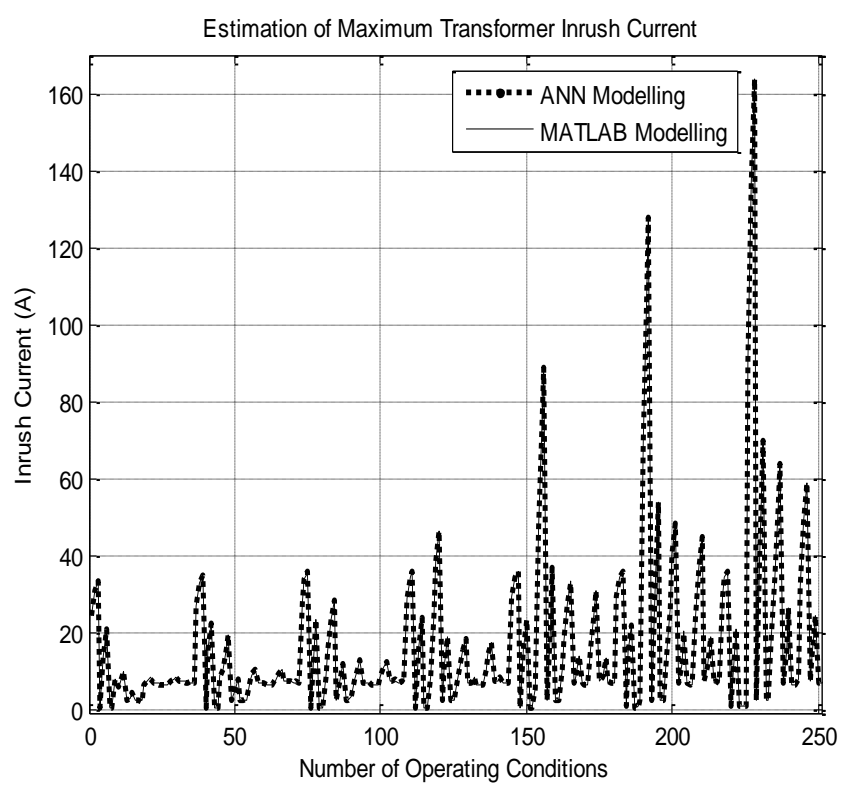

Fig 6: ANN Model for estimation of maximum inrush current with increasing operating conditions

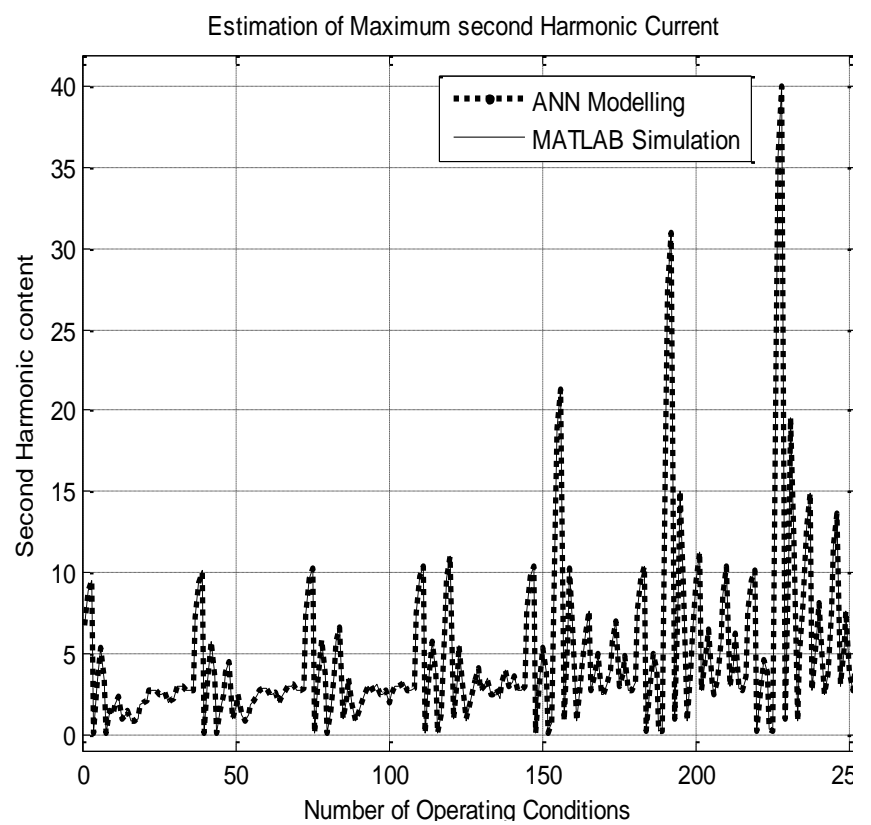

Fig 7: ANN Model for estimation of maximum second harmonic current with increasing operating conditions
Data sets are too large because of various operating conditions but ANN gives satisfactory performance. Some part of data is shown by Table 1 and 2. The first row of Table 1shows VA rating of transformer, applied voltage at primary side, switching angle, Remnant flux, maximum inrush current, ANN based maximum inrush current and percentage error of maximum value. Similarly, In Table 2 shows VA rating of transformer, Applied voltage at primary side, switching angle, Remnant flux, maximum second harmonic current, ANN based maximum second harmonic current and percentage error of maximum value.

Table 1. Comparison between actual and ANN based maximum inrush current

\begin{tabular}{|c|c|c|c|c|c|c|c|}
\hline $\begin{array}{c}\text { S } \\
\text { No }\end{array}$ & VA & Volt. & $\boldsymbol{\theta}$ & $\boldsymbol{\text { Tr }}$ & Simu. & ANN & \% error \\
\hline 1 & 5000 & 416 & 0 & 0 & 24.435 & 24.541 & -0.4338 \\
\hline 2 & 5000 & 33000 & 90 & 0.5 & 6.5927 & 6.6468 & -0.8206 \\
\hline 3 & 5000 & 36000 & 120 & 0.8 & 6.9974 & 6.9478 & 0.708835 \\
\hline 4 & 10000 & 416 & 120 & 0.8 & 8.5071 & 8.2719 & 2.764749 \\
\hline 5 & 10000 & 11000 & 90 & 0.8 & 7.9064 & 7.8853 & 0.266872 \\
\hline 6 & 10000 & 33000 & 120 & 0 & 6.4135 & 6.3953 & 0.283776 \\
\hline 7 & 10000 & 36000 & 120 & 0.8 & 6.9975 & 7.0161 & -0.26581 \\
\hline 8 & 15000 & 416 & 90 & 0.8 & 23.248 & 23.392 & -0.61941 \\
\hline 9 & 15000 & 11000 & 0 & 0.5 & 23.464 & 23.49 & -0.11081 \\
\hline 10 & 15000 & 33000 & 120 & 0 & 6.4132 & 6.3916 & 0.336805 \\
\hline 11 & 15000 & 36000 & 90 & 0.8 & 7.1929 & 7.4438 & -3.48816 \\
\hline 12 & 25000 & 416 & 90 & 0.5 & 16.201 & 16.364 & -1.00611 \\
\hline 13 & 25000 & 11000 & 0 & 0.5 & 38.344 & 38.229 & 0.299917 \\
\hline 14 & 25000 & 33000 & 120 & 0.8 & 6.4148 & 6.4893 & -1.16138 \\
\hline 15 & 25000 & 36000 & 120 & 0.5 & 6.9972 & 7.0768 & -1.1376 \\
\hline 16 & 50000 & 416 & 90 & 0 & 0.3692 & 0.48391 & -31.0699 \\
\hline 17 & 50000 & 11000 & 0 & 0.5 & 73.641 & 73.727 & -0.11678 \\
\hline 18 & 50000 & 33000 & 120 & 0.5 & 6.4141 & 6.3901 & 0.374176 \\
\hline 19 & 50000 & 36000 & 120 & 0.8 & 6.9985 & 6.9044 & 1.344574 \\
\hline 20 & 75000 & 416 & 120 & 0.5 & 0.5001 & 0.3402 & 31.98585 \\
\hline 21 & 75000 & 11000 & 0 & 0.8 & 127.61 & 127.64 & -0.02351 \\
\hline 22 & 75000 & 33000 & 0 & 0 & 26.007 & 26.104 & -0.37298 \\
\hline 23 & 75000 & 33000 & 90 & 0.8 & 20.016 & 20.026 & -0.04996 \\
\hline 24 & 75000 & 36000 & 0 & 0.8 & 44.736 & 44.828 & -0.20565 \\
\hline 25 & $1.0 \mathrm{E}+05$ & 416 & 120 & 0.8 & 0.7947 & 0.85014 & -6.96949 \\
\hline 26 & $1.0 \mathrm{E}+05$ & 11000 & 90 & 0 & 2.1988 & 2.3278 & -5.86684 \\
\hline 27 & $1.0 \mathrm{E}+05$ & 33000 & 0 & 0.8 & 63.797 & 63.802 & -0.00784 \\
\hline 28 & $1.0 \mathrm{E}+05$ & 36000 & 0 & 0 & 31.568 & 31.561 & 0.022174 \\
\hline & & & Average \% Error for complete data set -0.41183 \\
\hline
\end{tabular}

Table 2. Comparison between actual and ANN based maximum second harmonic current

\begin{tabular}{|c|c|c|c|c|c|c|c|}
\hline $\begin{array}{c}\text { S } \\
\text { No }\end{array}$ & VA & Volt. & $\boldsymbol{\theta}$ & $\boldsymbol{\Phi r}$ & $\begin{array}{c}\text { 2nd } \\
\text { Har. }\end{array}$ & $\begin{array}{c}\text { ANN } \\
\text { Har. }\end{array}$ & \% error \\
\hline 1 & 5000 & 416 & 0 & 0 & 6.6737 & 6.6715 & 0.032965 \\
\hline 2 & 5000 & 33000 & 90 & 0.5 & 2.7367 & 2.7418 & -0.18636 \\
\hline 3 & 5000 & 36000 & 120 & 0.8 & 2.7683 & 2.7602 & 0.292598 \\
\hline 4 & 10000 & 416 & 120 & 0.8 & 1.4347 & 1.4151 & 1.366139 \\
\hline 5 & 10000 & 11000 & 90 & 0.8 & 2.4667 & 2.4561 & 0.429724 \\
\hline 6 & 10000 & 33000 & 120 & 0 & 2.4984 & 2.5167 & -0.73247 \\
\hline 7 & 10000 & 36000 & 120 & 0.8 & 2.813 & 2.8146 & -0.05688 \\
\hline 8 & 15000 & 416 & 90 & 0.8 & 5.7513 & 5.7699 & -0.32341 \\
\hline 9 & 15000 & 11000 & 0 & 0.5 & 5.7759 & 5.7974 & -0.37224 \\
\hline 10 & 15000 & 33000 & 120 & 0 & 2.4985 & 2.5059 & -0.29618 \\
\hline 11 & 15000 & 36000 & 90 & 0.8 & 3.2111 & 3.2199 & -0.27405 \\
\hline 12 & 25000 & 416 & 90 & 0.5 & 3.3093 & 3.3118 & -0.07554 \\
\hline 13 & 25000 & 11000 & 0 & 0.5 & 9.6396 & 9.6234 & 0.168057 \\
\hline 14 & 25000 & 33000 & 120 & 0.8 & 2.7548 & 2.7492 & 0.203282 \\
\hline 15 & 25000 & 36000 & 120 & 0.5 & 2.7257 & 2.7413 & -0.57233 \\
\hline 16 & 50000 & 416 & 90 & 0 & 0.1090 & 0.1187 & -8.8791 \\
\hline 17 & 50000 & 11000 & 0 & 0.5 & 18.893 & 18.894 & -0.00529 \\
\hline 18 & 50000 & 33000 & 120 & 0.5 & 2.4989 & 2.4822 & 0.668294 \\
\hline 19 & 50000 & 36000 & 120 & 0.8 & 3.2231 & 3.1944 & 0.890447 \\
\hline 20 & 75000 & 416 & 120 & 0.5 & 0.1946 & 0.20685 & -6.25674 \\
\hline 21 & 75000 & 11000 & 0 & 0.8 & 31.034 & 31.033 & 0.003222 \\
\hline 22 & 75000 & 33000 & 0 & 0 & 6.2176 & 6.2041 & 0.217126 \\
\hline 23 & 75000 & 33000 & 90 & 0.8 & 6.4305 & 6.4262 & 0.066869 \\
\hline 24 & 75000 & 36000 & 0 & 0.8 & 10.331 & 10.327 & 0.038718 \\
\hline 25 & $1.0 \mathrm{E}+05$ & 416 & 120 & 0.8 & 0.2477 & 0.23428 & 5.448382 \\
\hline 26 & $1.0 \mathrm{E}+05$ & 11000 & 90 & 0 & 0.9075 & 0.91796 & -1.15262 \\
\hline 27 & $1.0 \mathrm{E}+05$ & 33000 & 0 & 0.8 & 14.889 & 14.89 & -0.00672 \\
\hline 28 & $1.0 \mathrm{E}+05$ & 36000 & 0 & 0 & 7.5527 & 7.565 & -0.16286 \\
\hline & & & $A$ & 9 & & & \\
\hline
\end{tabular}

Average \% Error for complete data set -0.29116 


\section{ANALYSIS}

Table 3 and 4 shows correlation values of maximum inrush current and second harmonic current content with respect to input variables. Correlation value indicates the similarity in between two data sets. Positive value indicates positive similarity. Similarly, for negative values indicates negative similarity.

Table 3. Comparison of correlation value in between actual and ANN based maximum inrush current

\begin{tabular}{|c|c|c|c|}
\hline \multirow{2}{*}{ S No. } & \multirow{2}{*}{ Input Variable } & \multicolumn{2}{|c|}{$\begin{array}{c}\text { Correlation Value } \\
\text { (Maximum Inrush } \\
\text { Current) }\end{array}$} \\
\cline { 3 - 4 } & & $\begin{array}{c}\text { Actual } \\
\text { Data }\end{array}$ & $\begin{array}{c}\text { ANN } \\
\text { Data }\end{array}$ \\
\hline 1 & KVA & 0.3582 & 0.3582 \\
\hline 2 & Voltage & -0.1338 & -0.1338 \\
\hline 3 & Switching Angle & -0.5420 & -0.5421 \\
\hline 4 & Remanent Flux & 0.2090 & 0.2091 \\
\hline
\end{tabular}

Table 4. Comparison of correlation value in between actual and ANN based maximum second harmonic current

\begin{tabular}{|c|c|c|c|}
\hline \multirow{2}{*}{ S No } & \multirow{2}{*}{ Input Variable } & \multicolumn{2}{|c|}{$\begin{array}{c}\text { Correlation Value } \\
\text { (Maximum Second } \\
\text { Harmonic current) }\end{array}$} \\
\cline { 3 - 4 } & & $\begin{array}{c}\text { Actual } \\
\text { Data }\end{array}$ & $\begin{array}{c}\text { Actual } \\
\text { Data }\end{array}$ \\
\hline 1 & KVA & 0.3942 & 0.3942 \\
\hline 2 & Voltage & -0.1297 & -0.1297 \\
\hline 3 & Switching Angle & -0.4642 & -0.4642 \\
\hline 4 & Remanent Flux & 0.1586 & 0.1585 \\
\hline
\end{tabular}

\section{CONCLUSION}

Results from this study evidently prove that developed ANN model is reliable to estimate maximum inrush current and second harmonic current content, with higher accuracy. The proposed system provides a faster and reliable response. Such a system could be very useful in predicting of maximum inrush current for large rating of transformer where large electromagnetic transient forces exist. ANN Model has beauty to train network with data of non linearity which gives almost exact matching with target values. Therefore, ANN model is able to predict maximum inrush current value with an acceptable average of percentage error and second harmonic current content again with an acceptable average percentage error. Results of the study suggest that LM training is faster than the general delta rule and it needs less input pattern to training than the other one. If larger and more homogenous data sets are provided than it will result in better training of ANN models with smaller errors and biases.

\section{REFERENCES}

[1] L. F. Blume, G. Camilli, S. B. Farnham, and H. A. Peterson, "Transformer magnetizing inrush currents and influence on system operation," AIEE Trans. Power App. Sys f. , vol. 63, pp. 366-375, Jan. 1944.

[2] E. 0. Schweitzer, R. R. Larson, and A. J . Flechsig, Jr., "An efficient inrush current detection algorithm for digital computer Proc". IEEE," in Power Eng. Sue. Summer Meet. (Mexico), pt. A77, pp. 510, July 1977
[3] R. Yacamini and A. Abu-Nasser, "Numerical calculation of inrush current in single phase transformers." Proc. Inst. Elec. Eng., vol. 128, pt. B, no. 6, pp. 327-334, Nov. 1981.

[4] R. Yacamini and A. Abu-Nasser, , "The calculation of inrush current in three phase transformers," Proc. Inst. Eke. Eng., vol. 133, pt. B, no. I, pp 31-40, Jan. 1986

[5] C Paul. Y. Ling and Amitava Basak. "Investigation of Magnetizing Inrush Current in a Single-phase Transformer." IEEE transactions on magnetics. vol 24. no 6, pp 3217 - 3222, 1988.

[6] R. Yacamini and H. Bronzeado, "Transformer inrush calculations using a coupled electromagnetic model," Proc. Inst. Elect. Eng., Sci., Meas. Technol., vol. 141, no. 6, pp. 491-498, Nov. 1994.

[7] Stringer, N.T., Lawhead, L; Wilkerson, T.; Biggs, J., Rockefeller G.D. "Real-time transient testing and performance of transformer differential relays" IEEE, Volume: 2, 8-12, pp1142 - 1150, Oct. 1995.

[8] K. Yabe, "Power differential method for discrimination between fault and magnetizing inrush current in transformers," IEEE Trans. Power Del., vol. 12, no. 3, pp. 1109-1118, Jul. 1997.

[9] Stringer, N.T., Lawhead, L., Wilkerson, T., Biggs, J., Rockefeller, G.D. " Testing and performance of transformer differential relays" IEEE, Volume: 3, Issue: 4, pp:36 - 420, July-Aug. 1997.

[10] Z Q Bo, R K Aggarwal. A T Johns, “A new relaying principle for power transformer protection using transient comparison technique," Developments in Power System Protection, pp. 139-142, 25-27th March 1997.

[11] K. S. Smith, L. Ran, and B. Leyman, "Analysis of transformer inrush transient in offshore electrical systems," Proc. Inst. Elect. Eng., Gen.,Transm. Distrib., vol. 146, no. 1, pp. 89-95, Jan. 1999.

[12] J. J. Rico, E. Acha, and M. Madrigal, "The study of inrush current phenomenon using operational matrices," IEEE Trans. Power Del., vol. 16, no. 2, pp. 231-237, Apr. 2001.

[13] Guzman, A.; Zocholl, S.; Benmouyal, G.; Altuve, H.J.,"a current-based solution for transformer differential protection-part I: Problem Statement", IEEE Transactions on Power Delivery, Volume 16, pp 485491, October 2001.

[14] Saied, M.M., "A study on the inrush current phenomena in transformer substations", IEEE Volume: 2, vol.2, 30, pp1180 - 1187, Sept.-4 Oct. 2001.

[15] P. L. Mao and R. K. Aggarwal, "A novel approach to the classification of the transient phenomena in power transformers using combined wavelet transform and neural network," IEEE Trans. Power Del., vol. 16, no. 4, pp. 654-660, , Oct. 2001.

[16] Guzman, A.; Zocholl, S.; Benmouyal, G.; Altuve, H.J.,"a current-based solution for transformer differential protection-part II: relay description and evaluation", IEEE Transactions on Power Delivery Volume 17, pp 886-893, ,October 2002. 
[17] Controlled Switching of HVAC CBs-Planning, Specifications \& Testing, CIGRÉ SC A3 Working Group A3.07, Jan. 2004.

[18] Andreas Ebner, Michael Bösch, Renato Cortesi. "Controlled Switching of Transformers - Effects of Closing Time Scatter and Residual Flux Uncertainty." IEEE: Universities Power Engineering Conference.. 43rd .pp 1-5, 2008.

[19] Yunfei Wang, Sami G. Abdulsalam, and Wilsun Xu, "Analytical Formula to Estimate the Maximum Inrush Current", IEEE Transactions on Power Delivery, VOL. 23, NO. 2, pp 1266-68, April 2008.

[20] M. G. Vanti, S. L. Bertoli, S. H. L. Cabral, A. G. Gerent, Jr., and P. Kuo-Peng, "Semianalytic Solution for a Simple Model of Inrush Currents in Transformers" IEEE Transactions on Magnetics, VOL. 44, NO. 6, June 2008.

[21] N. Chiesa and H. K. Høidalen, "Systematic switching study of transformer inrush current: Simulation and measurements," presented at the Int. Conf. Power System Transients, Kyoto, Japan, Jun. 2009.

[22] M. Jamali, M. Mirzaie, S. Asghar Gholamian. "Calculation and Analysis of Transformer Inrush Current Based on Parameters of Transformer and Operating
Conditions," Electronics and Electrical Engineering. , Kaunas: Technologija, No. 3(109). pp. 17-20, 2011.

[23] Singh P K and D K chaturvedi "Modeling and Simulation of Single Phase Transformer Inrush Current using Neural Netwrok" National Conference ETEIC2012 Proceedings, pp 296-299, April ,2012.

[24] Puneet Kumar Singh, D K Chaturvedi, "Neural Network based Modeling and Simulation of Transformer Inrush Current", IJISA, vol.4, no.5, pp.1-7, 2012.

[25] Yousefizadeh, H. and Zilouchian, A. Neural network structures. In Zilouchian A and Jamshidi M, editors. Intelligent control systems using soft computing methodologies. Boca Raton, FL: CRC Press, 39-66, 2001.

[26] Zilouchian, A. Fundamentals of neural networks. In Zilouchian A and Jamshidi M, editors. Intelligent control systems using soft computing methodologies. Boca Raton, FL: CRC Press, 17-38, 2001.

[27] Chaturvedi D. K. "Soft Computing Techniques and its Applications in Electrical Engineering" Springer, Vol 103, 2008.

[28] Yegnanarayana, B. Artificial Neural Networks. Prentice Hall of India, 2009. 